\title{
Recent Strengthening of Greenland Blocking Drives Summertime Surface Warming over Northern Canada and Eastern Siberia ${ }^{\mathscr{O}}$
}

\author{
SAI WANG \\ Center for Monsoon System Research, Institute of Atmospheric Physics, and College of Earth and \\ Planetary Sciences, University of the Chinese Academy of Sciences, Beijing, China
}

DEBASHIS NATH

Center for Monsoon System Research, Institute of Atmospheric Physics, Chinese Academy of Sciences, Beijing, China

WEN CHEN

Center for Monsoon System Research, Institute of Atmospheric Physics, and College of Earth and Planetary Sciences, University of the Chinese Academy of Sciences, Beijing, China

LIN WANG

Center for Monsoon System Research, Institute of Atmospheric Physics, Chinese Academy of Sciences, Beijing, China

(Manuscript received 25 June 2018, in final form 1 March 2019)

\begin{abstract}
In the last three decades, rapid surface warming is observed in the land areas of northern high latitudes during boreal summer months. Although the warming trend is thought to be driven by early snowmelt, the exact causes, especially its relationship with atmospheric circulation changes, remain a subject of debate. By analyzing ERA-Interim data, this study examines the possible factors for rapid subarctic warming. It is found that more than half of the warming trend over the entire subarctic and $80 \%$ over northern Canada and eastern Siberia (regions with maximum amplification) can be explained by enhanced downward infrared radiation (IR). Downward IR is largely driven by horizontal atmospheric moisture flux convergence and warm-air advection. The positive trend in geopotential height over the Greenland region is key for moisture flux convergence over northern Canada and eastern Siberia through changes in the storm tracks. An enhanced summertime blocking activity in the Greenland region seems responsible for the positive trend in geopotential heights.
\end{abstract}

\section{Introduction}

In recent decades, observational studies showed that surface warming is strongest over the Arctic than at any other latitudes, a phenomenon called Arctic amplification (AA) (Francis and Skific 2015; Johannessen et al. 2004; Overland et al. 2008; Polyakov et al. 2003; Screen and Simmonds 2010a,b; Serreze and Barry 2011; Davy et al. 2018). The recent decades have also experienced

Supplemental information related to this paper is available at the Journals Online website: https://doi.org/10.1175/JCLI-D-180410.s1.

Corresponding author: Debashis Nath, debashis@mail.iap.ac.cn an exceptional number of unprecedented extreme weather events, such as extended cold spells and extreme heat waves in the northern midlatitudes (Coumou and Rahmstorf 2012; Lehmann and Coumou 2015; World Meteorological Organization 2011; Peterson et al. 2013; Sutton and Dong 2012; Tang et al. 2014, 2013). Some studies argued that AA weakens the jet stream, increases the meridional flow, amplifies the waves, and triggers more persistent extreme weather events (Coumou et al. 2015, 2014; Francis and Vavrus 2012, 2015; Overland et al. 2016; Tang et al. 2013; Liu et al. 2012). However, several other studies argued that the warmer Arctic is a result of changes in atmospheric circulation (Ding et al. 2014; Trenberth et al. 2014; Gong et al. 2017; Lee et al. 2011a,b, 2017). For example, some 

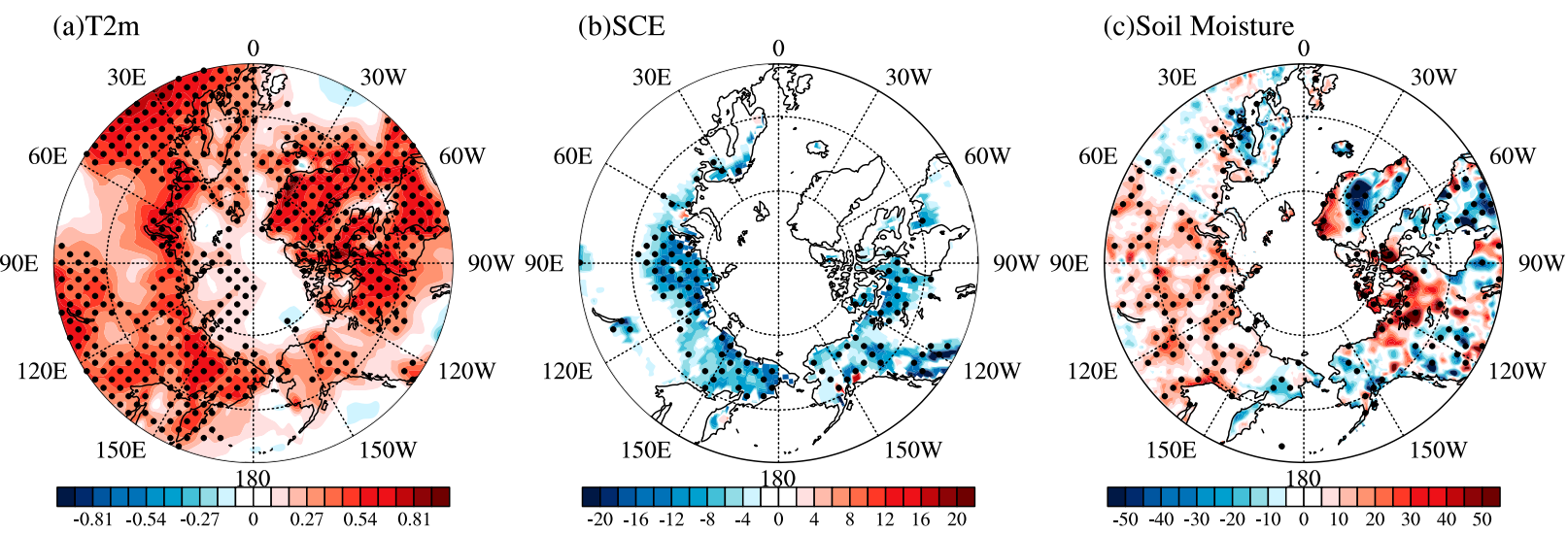

FIG. 1. Linear trend (decade ${ }^{-1}$ ) of (a) summer (JJA-averaged) surface air temperature (T2m; K), (b) snow-cover extent in June (SCE; \%), and (c) summer soil moisture (mm) during 1979-2016. The dotted areas indicate the linear trends that are statistically significant at the $95 \%$ confidence level. The surface air temperature is from the ERA-Interim dataset, the snow cover is from NSIDC EASE Grid snow-cover data, and the soil moisture is from NOAA CPC dataset.

studies indicated that the AA during winter months is largely due to enhancement of the downward IR, which is driven by horizontal atmospheric water flux and warm-air advection into the Arctic (Gong et al. 2017; Lee et al. 2011a,b, 2017).

In the Northern Hemisphere, Greenland often experiences frequent blocking events (Davini et al. 2012, 2014). The occurrence and intensity of Greenland blocking can be measured using the Greenland blocking index (GBI; Fang 2004; Hanna et al. 2013). Significant positive trends in the summer GBI were observed in the last few decades (McLeod and Mote 2016; Hanna et al. 2018) and some studies have attributed this positive trend in summer GBI to the summer AA (Francis and Vavrus 2012; Overland et al. 2012). During boreal summer months, the most apparent AA signal can be found over the subarctic continents (Serreze et al. 2009; Francis and Vavrus 2012, 2015), with the largest amplitude of the warming over eastern Siberia, Alaska, northern Canada, and Greenland (Fig. 1a). These studies argued that the amplified summer warming over the subarctic continents is due to an earlier snowmelt (Francis and Vavrus 2012; Overland et al. 2012). These changes in snow cover may have significant influences on summer surface temperature because of the snow-hydrological effect (Yasunari et al. 1991). An earlier snowmelt decreases the soil moisture content, which could persist even further into the following summer season (Matsumura and Yamazaki 2012; Matsumura et al. 2010). However, some suggested that the recent warming in the northeastern Canada and Greenland sector is due to stronger anticyclonic circulation over Greenland and the Arctic Ocean (Ding et al. 2014; Hanna et al. 2013). From the above discussion, we can argue that the underlying physical mechanisms for summer AA are not yet clear.
Although some of the previous studies have focused on the summer warming trend in the North American high latitudes, no attention has been paid to the warming trend in the Eurasian high latitudes. Meanwhile, the significant reduction in June snow cover, an effective measure of earlier or later spring snowmelt over highlatitude land areas (Fig. 1b; Matsumura and Yamazaki 2012), is consistent with the previous findings (Brown et al. 2010; Groisman et al. 2006). However, a significant decreasing trend in summer soil moisture can only be seen in some regions confined to the northeastern part of eastern Siberia, Alaska, and southern Greenland (Fig. 1c). A significant increasing trend in summer soil moisture is observed over most of eastern Siberia and northern Canada, which is inconsistent with an early melt of snow cover. This implies that the recent subarctic warming cannot be explained fully by the snow-hydrological mechanism, which warrants a further investigation to identify the underlying physical mechanisms. Therefore, this study examines the possible factors for the rapid warming in high latitudes and the role of large-scale circulation changes in driving the warming trend. This study may improve our understanding of the processes responsible for the summer AA, which is a topic at the core of rapid climate changes in the high latitudes.

\section{Data and methods}

\section{a. Data}

The monthly mean downward IR and other surface heat flux datasets are obtained from the European Centre for Medium-Range Weather Forecasts (ECMWF) interim reanalysis (ERA-Interim; Dee et al. 2011). The surface radiation data from ERA-Interim are consistent with the in situ measurements (Cox et al. 2012; Shi 
et al. 2010; Zib et al. 2012). The present study also employs the monthly mean surface temperature at $2 \mathrm{~m}$, vertically integrated total column water, geopotential height, relative humidity, and horizontal winds from ERA-Interim. These ERA-Interim data have a horizontal resolution of $2.5^{\circ} \times 2.5^{\circ}$ and are available from 1979 to the present. The snow-cover extent dataset used in the present study is the Northern Hemisphere 25-km Equal Area Special Sensor Microwave Imager (SSM/I) Earth (EASE). Weekly Snow Cover and Sea Ice Extent, version 4, products (Brodzik and Armstrong 2013) are obtained from the National Snow and Ice Data Center (NSIDC). The EASE gridded snow-cover data are available after October 1966. In the present study, monthly mean global soil moisture datasets is available from the National Oceanic and Atmospheric Administration (NOAA) Climate Prediction Center (CPC) Leaky-Bucket Model (Fan and Dool 2004). The CPC soil moisture dataset has a $0.5^{\circ}$ resolution and is available from 1948 onward. Monthly mean global land surface precipitation data are derived from centennial GPCC Full Data Reanalysis datasets (Schneider et al. 2011), and the prediction dataset has a resolution of $1^{\circ}$ and is available from 1901 onward.

\section{b. Methods}

To identify the dominant mechanism driving the warming trend, we estimate the contribution of different factors to the surface temperature trend by analyzing the changes in surface energy balance. According to Lesins et al. (2012), the surface energy budget can be written as

$$
S_{d}+S_{u}+I_{d}+I_{u}+F_{\mathrm{sh}}+F_{\mathrm{lh}}+C=0,
$$

where $S$ and $I$ are the shortwave and infrared radiation, respectively, $F_{\mathrm{sh}}$ is the surface sensible heat flux, $F_{\mathrm{lh}}$ is surface latent heat flux, and $C$ is conduction below from Earth's surface. The subscript $d$ denotes downward and $u$ denotes upward, and all the atmospheric energy fluxes are defined as positive when they are directed downward. Term $I_{u}$ is expressed as $-\varepsilon \sigma T_{s}^{4}$, where $\varepsilon$ is the surface emissivity, $\sigma$ is the Stefan-Boltzmann constant, and $T_{s}$ is the skin temperature. The differential operator $\Delta$ represents the trend. The equation for the trend in the surface energy budget can be written as

$$
\Delta S_{d}+\Delta S_{u}+\Delta I_{d}-\varepsilon \sigma \Delta T_{s}^{4}+\Delta F_{\mathrm{sh}}+\Delta F_{\mathrm{lh}}+\Delta C=0 .
$$

Equation (2) can be rewritten as

$$
\Delta T_{s}=\left(\Delta S_{d}+\Delta S_{u}+\Delta I_{d}+\Delta F_{\mathrm{sh}}+\Delta F_{\mathrm{lh}}+\Delta C\right) / 4 \varepsilon \sigma T_{s}^{3} .
$$

According to Eq. (3), the trend in skin temperature is proportional to the trend in the energy fluxes. As the surface temperature is highly correlated with the skin temperature in all seasons over the Arctic (Chen et al. 2002), the trend in surface temperature is also proportional to the trend in the upward and downward shortwave radiation, downward IR, and the surface sensible and latent heat fluxes. Furthermore, the change in surface temperature may also be affected by horizontal temperature advection and adiabatic heating. Following Gong et al. (2017), surface temperature at each data point could be expressed as follows:

$$
f \cong f\left(x_{1}, x_{2}, x_{3}, x_{4}, x_{5}\right),
$$

where $f$ indicates surface temperature, and $x_{1}, x_{2}, x_{3}, x_{4}$, and $x_{5}$ represent turbulent heat flux (THF; sum of the surface sensible and latent heat fluxes), downward IR, net shortwave radiation (SWR; sum of the downward and upward shortwave radiation), horizontal temperature advection, and the adiabatic heating, respectively. The linear trends in surface temperature can be expressed as

$$
\Delta f=\sum_{i=1}^{N}\left(\partial f / \partial x_{i}\right) \Delta x_{i},
$$

where $\Delta f$ and $\Delta x_{i}$ are the linear trends in surface temperature $f$ and $x_{i}$, respectively; $\partial f / \partial x_{i}$ is the change in $f$ with respect to changes in $x_{i}$, which can be estimated by calculating a linear regression coefficient at each grid point between $f$ and $x_{i}$; and $\left(\partial f / \partial x_{i}\right) \Delta x_{i}$ is the linear trend in surface temperature $f$ associated with each of the independent variables for $i=1, \ldots, 5$. The contributions of each of the variables toward the actual trend in surface temperature $\Delta f$ can be expressed as

$$
C_{i}=\frac{\left(\partial f / \partial x_{i}\right) \Delta x_{i}}{\Delta f_{i}} \times 100 \% .
$$

Because of the offset effect, contribution of the linear trends over some regions exceeds $100 \%$, and therefore, we set the value to $100 \%$ when this condition occurred.

We constructed the projection time series of trend pattern using the method mentioned in Feldstein (2003). The projection time series is defined as

$$
P(t)=\frac{\sum_{i, j} x(\lambda, \theta, t) X(\lambda, \theta)}{\sum_{i, j} X(\lambda, \theta)^{2} \cos \theta},
$$

where $i$ and $j$ correspond to the longitudinal and latitudinal grid points, respectively; $x(\lambda, \theta, t)$ is the variable of interest; $X(\lambda, \theta)$ is the linear trend pattern of the variable; and $t, \theta$, and $\lambda$ stand for time, latitude, 
T2m trend
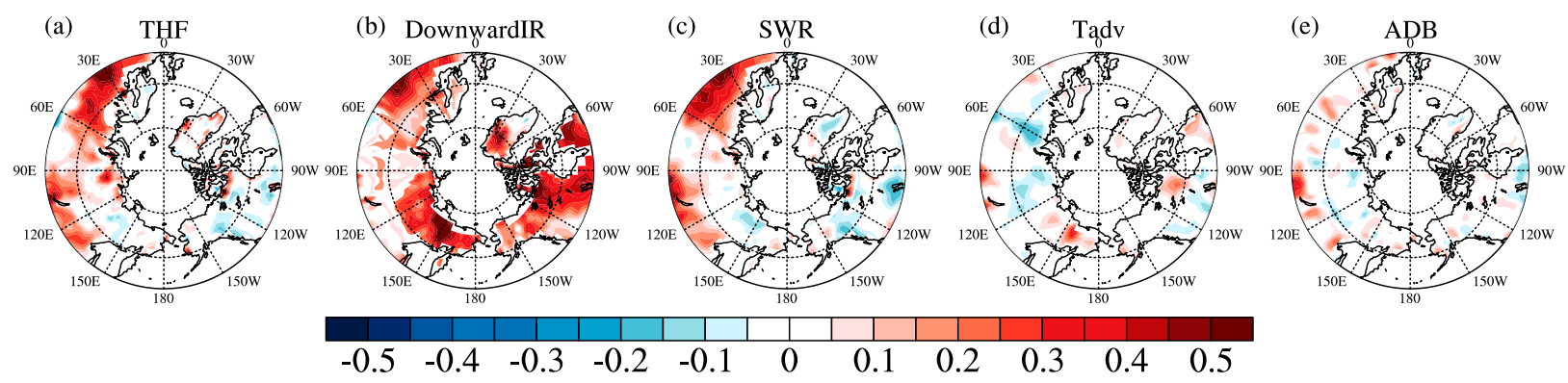

\section{Contribution}
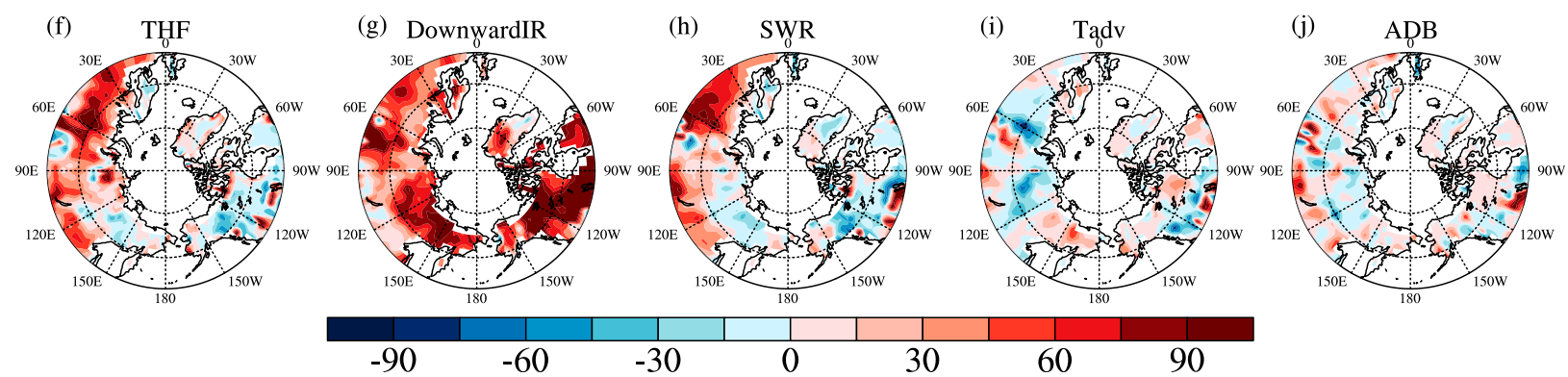

FIG. 2. (top) Linear trends (decade ${ }^{-1}$ ) of summer-mean surface air temperature (K) during 1979-2016 obtained by linear regression against (a) turbulent heat flux (THF), (b) downward IR, (c) net shortwave radiation (SWR), (d) horizontal temperature advection (Tadv), and (e) adiabatic heating (ADB). (bottom) The contribution (\%) of summer-mean (f) THF, (g) downward IR, (h) SWR, (i) Tadv, and (j) ADB to the surface temperature trends.

and longitude, respectively. The nonparametric MannKendall technique (Mann 1945) is used to estimate the significance of the linear trend. To detect the blocking event, a two-dimensional (2D) blocking index, which is an extension of the Tibaldi and Molteni (1990) index developed by Davini et al. (2012), is used in this study.

\section{Results}

\section{a. Attribution of the surface temperature trend}

In this section, we evaluate the contribution of different processes in the warming trend by analyzing the relationship between surface temperature and changes in surface energy fluxes. Since warming has occurred predominantly over the subarctic landmasses [e.g., extended data Fig. 2c of Ding et al. (2014)], we mask the observations over ocean and emphasize our analysis over land only. Figures $2 \mathrm{a}-\mathrm{d}$ show the linear trend in surface temperature from 1979 to 2016, which is obtained by linear regression with turbulent heat flux, downward IR, net shortwave radiation, horizontal temperature advection, and adiabatic heating, respectively. The resulting calculations suggest that the trend in surface temperature explained by the changes in turbulent heat flux can only be seen in a small region and are less organized over high-latitude Northern Hemisphere land areas (Fig. 2a). It implies that the recent Arctic warming during summer cannot be fully explained by the changes in local turbulent heat fluxes. Second, the magnitude and structure of the surface temperature trend explained by downward IR bears a close resemblance to that of the surface temperature trend (Figs. 1a, 2b). It indicates the relative significance of downward IR on other factors in driving the summer AA, particularly over northern Canada and eastern Siberia. As far as net shortwave radiation is concerned, the trend is negative over eastern Siberia, northwestern Canada, and southern Greenland (Fig. 2c). It is indicative of the fact that the changes in net shortwave radiation have a negative contribution to the warming trend over these regions. Although the regressed trend with horizontal temperature advection is positive in some regions (Fig. 2d), such as eastern Siberia and northeastern Canada, its magnitude is much smaller than the downward IR. Last, the adiabatic heating appears to have no significant contribution to the trend in summer surface temperature (Fig. 2e).

To further quantify the contributions of each of the variables in actual surface temperature trend, we calculate the ratio of the observed linear trend in 


\section{Corr with T2m}
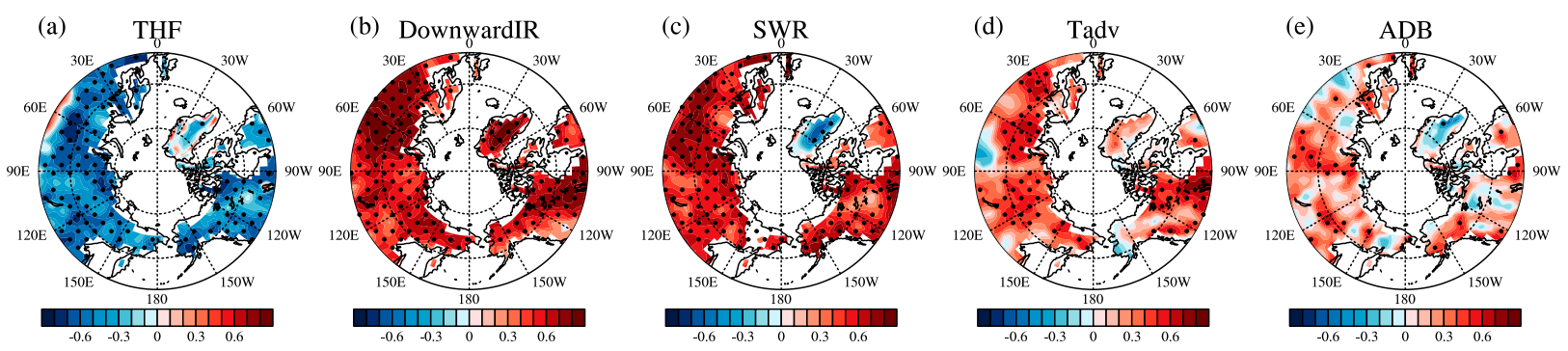

Trend
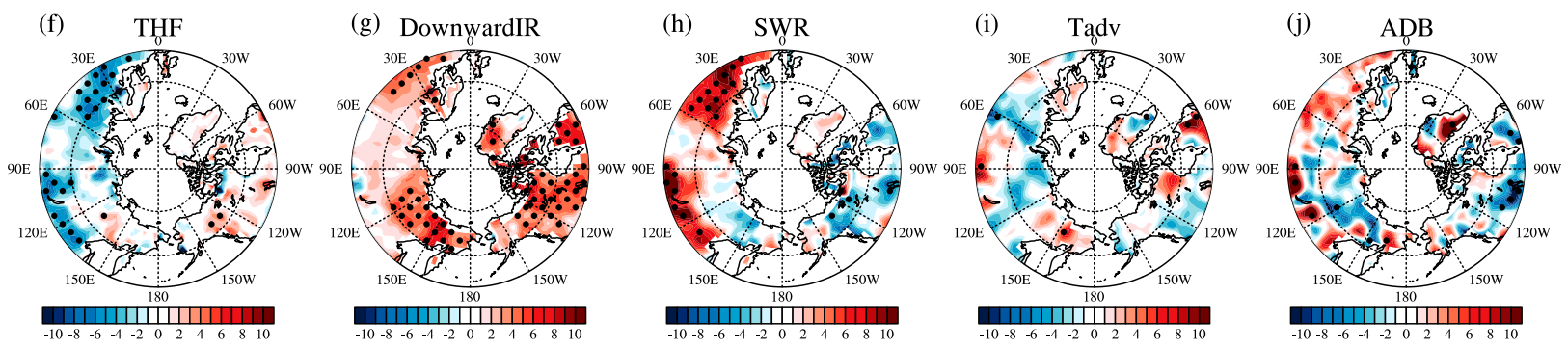

FIG. 3. (top) The correlation coefficients between summer-mean surface air temperature and (a) THF, (b) downward IR, (c) SWR, (d) Tadv, and (e) ADB. (bottom) The linear trend (decade ${ }^{-1}$ ) of summer-mean (f) THF (W m $\left.{ }^{-2}\right)$, (g) downward IR (W m ${ }^{-2}$ ), (h) SWR (W m${ }^{-2}$ ), (i) Tadv $\left(10^{-4} \mathrm{~K} \mathrm{~s}^{-1}\right)$, and (j) ADB $\left(10^{-4} \mathrm{~K} \mathrm{~s}^{-1}\right)$ during 1979-2016. The dotted areas indicate the values that are statistical significant at the $95 \%$ confidence level.

surface temperature to the trend explained by each of the variables (methods). Figures $2 \mathrm{f}-\mathrm{j}$ show the spatial pattern of contribution of turbulent heat flux, downward IR, net shortwave radiation, horizontal temperature advection, and adiabatic heating to the linear trend in surface temperature during 1979-2016, respectively. It reveals that the contribution of downward IR (Fig. $2 \mathrm{~g}$ ) often exceeds $50 \%$, whereas each of the other four variables contribute weakly to the total trend. Furthermore, the contribution of downward IR even exceeds $80 \%$ over eastern Siberia and northern Canada. However, it is noteworthy that over northwestern Canada the net shortwave radiation counteracts the strong warming trend (Fig. 2h), and therefore it displays a relatively weaker warming trend over there. The contribution of horizontal temperature advection though accounts for a substantial fraction of the surface temperature trend over eastern Siberia and northeastern Canada (Fig. 2i), yet its contribution is much weaker than the downward IR.

The corresponding trends in Figs. $2 \mathrm{f}-\mathrm{j}$ are the product of the regression coefficient and the trend. Therefore, in Figs. $2 \mathrm{f}-\mathrm{j}$, a larger contribution of any variable signifies its stronger covariability with surface temperature and a stronger trend in the corresponding variable as well. To illustrate the covariability of surface temperature with the individual variables $x_{i}$ and their individual trends separately, we plotted the correlation map and linear trend in Fig. 3. Figures 3a-e show the correlation coefficient map of surface temperature with the turbulent heat flux, downward IR, net shortwave radiation, horizontal temperature advection, and adiabatic heating, respectively. The correlation coefficients between the surface temperature and turbulent flux are negative at all grid points, except over Greenland (Fig. 3a), which corresponds to an increase in surface temperature and upward turbulent flux (Gong et al. 2017). Second, for downward IR, it is positively correlated with surface temperature at all grid points (Fig. 3b), implying its strong covariability with summer surface temperature over the subarctic. Third, the correlation of surface temperature with net shortwave radiation is positive almost at all the grid points, except over Greenland, where it is negative (Fig. 3c). Over Greenland, the air temperature is strongly affected by downward IR from the atmosphere (Fig. 3b), and an increasing cloud cover corresponding to an enhancement in downward IR decreases the downward shortwave radiation. Fourth, the correlation pattern with near-surface horizontal temperature advection is positive at most of the places (Fig. 3d) over Arctic, while the covariability with adiabatic heating exhibits a complex pattern, with a positive coefficient in some regions and a negative coefficient in others (Fig. 3e).

Figures $3 \mathrm{f}-\mathrm{j}$ show the linear trend in turbulent heat flux, downward IR, net shortwave radiation, horizontal 
temperature advection, and adiabatic heating, respectively. There is almost no significant trend in turbulent heat flux over the land areas except for northwestern Canada (Fig. 3f), whereas a strong trend in the downward IR appears over a large part of the land region (Fig. 3g), particularly over northern Canada and eastern Siberia. Therefore, the dominance of the downward IR contribution to the linear trend in surface temperature in Fig. $2 \mathrm{~g}$ can be understood from its covariability with surface temperature change (Fig. $3 b$ ) and large positive linear trend (Fig. 3g) in the downward IR. For the net shortwave radiation, the negative trends over the land areas (Fig. 3h) imply a cooling contribution to the surface temperature trend in some regions. The changes in the net shortwave radiation are mainly due to the changes in the cloud cover (supplementary Figs. 1a-c), whereas the negative trend in the net shortwave radiation is mainly due to an increasing trend in the high cloud cover (supplementary Fig. 1a). However, the positive trend in the net shortwave radiation has occurred over eastern Europe (Fig. 3h), which is due to the decreasing trend in the cloud cover at all pressure levels (supplementary Figs. 1a-c). In addition, trends in surface albedo is insignificant and less organized over the subarctic regions (supplementary Fig. 1d), indicating its weaker contributions to the changes in net shortwave radiation. The horizontal temperature advection trend, though, appears over the downward-IR-dominated region (Fig. 3i), but it is confined to a very small region and cannot be attributed to the widespread warming over northern Canada and eastern Siberia. Though its covariability with surface warming is strong, the weaker contribution might have arisen because of the smaller magnitude of the trend. Finally, an increase in adiabatic heating trend appears over the Greenland region and northeastern part of eastern Siberia (Fig. 3j); however, it contributes weakly to the surface temperature warming. Therefore, by analyzing Fig. 3, we find that only downward IR can explain the warming trend over northern Canada and eastern Siberia satisfactorily; it contributes the most to the summer warming over the subarctic. We should note that none of the above processes could explain the warming trend that occurred over southern Greenland even though there are stronger trends in the adiabatic heating term. Our methodology is based on the presumption that the same process is driving the interannual and long-term variability in the surface temperature trend. This assumption may not be valid over Greenland, and the physical mechanism driving the warming trend over Greenland needs further investigation.

The above analyses showed that the changes in local turbulent heat fluxes are less important in contributing to the warming trend, and therefore we are curious about the role of ground conduction term. Although gridded data are not available, we can estimate the conductive flux based on Eq. (1). The conductive flux term can be expressed as $-\left(S_{d}+S_{u}+I_{d}+I_{u}+F_{\mathrm{sh}}+F_{\mathrm{lh}}\right)$. Although there are significant positive trends in the conductive flux across the Arctic coastline (supplementary Fig. 2d), it contributes weakly to the surface temperature trend (supplementary Figs. 2a,b) because of its weak covariability with surface temperature (supplementary Fig. 2c). In most of the regions, the correlation between the surface temperature and conductive flux is negative, which implies that an increase in surface temperature inhibits the increase in the upward heat conduction.

\section{b. Factors for the downward IR enhancement}

Considering the importance of downward IR change on surface temperature trend in the subarctic continent, here we investigate the factors related to the enhancement of downward IR. Previous studies showed that the midlatitude winter circulation contributes the most to the increase in downward IR over Arctic Ocean on the intraseasonal time scale (Woods et al. 2013; Gong and Luo 2017; Gong et al. 2017). In the recent decades, the long-term increasing trend in intraseasonal moisture intrusions accounts for the positive trend in winter-mean downward IR over the Arctic Ocean (Doyle et al. 2011; Gong et al. 2017; Park et al. 2015; Woods et al. 2013). Therefore, an obvious question is whether a similar mechanism is responsible for the positive trend in summer-mean downward IR over the subarctic continent. To answer this question, we employ the Gong et al. (2017) methodology to compute the daily IR index by projecting the daily downward IR field onto the downward IR trend pattern in Fig. 3 (see section 2b). As shown in Fig. 3, an increase in downward IR over eastern Siberia and northern Canada contributes the most to the warming trend in those regions. Therefore, two daily IR indices are computed, one for northern Canada $\left(55^{\circ}-72.5^{\circ} \mathrm{N}, 250^{\circ}-300^{\circ} \mathrm{E}\right.$; region 1$)$ and other for eastern Siberia $\left(60^{\circ}-70^{\circ} \mathrm{N}, 120^{\circ}-170^{\circ} \mathrm{E}\right.$; region 2$)$. The IR indices measure the day-to-day variations in the amplitude of downward IR trend pattern. Figure 4 displays the time series of daily IR1 (northern Canada) and daily IR2 indices (eastern Siberia) from 1979 to 2016 (JJA). It can be seen that both the time series are dominated by the intraseasonal variability and display an obvious upward trend for the analyzed period (Fig. 4). Figure 5 display the trends of downward IR and total column water (TCW) during 1979-2016 (JJA), which is obtained by regressing the variables against the IR1 and IR2 indices, respectively. An increase in the IR1 (IR2) index corresponds to an increase in downward IR over northern Canada (eastern Siberia) 

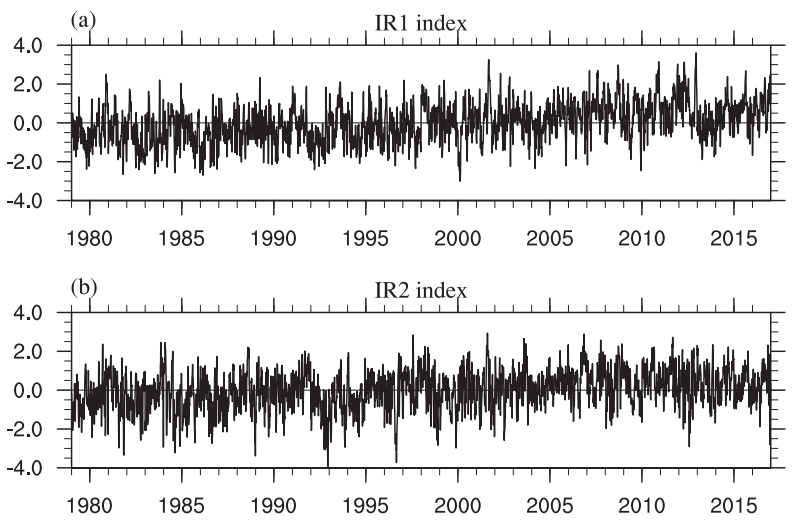

FIG. 4. The projection time series of downward IR over (a) northern Canada (IR1; $55^{\circ}-72.5^{\circ} \mathrm{N}, 60^{\circ}-110^{\circ} \mathrm{W}$ ) and (b) east Siberia (IR2; $60^{\circ}-70^{\circ} \mathrm{N}, 120^{\circ}-170^{\circ} \mathrm{E}$ ) for the $1979-2016 \mathrm{JJA}$ time period. Amplitudes are scaled by one standard deviation of the corresponding time series.

(Figs. 5a,c). It should be noted that the magnitudes of the downward IR trend that are calculated using the IR indices are different from the downward IR trend shown in Fig. 3g. Being an excellent emitter of downward IR (Walsh and Chapman 1998; Lee et al. 2011b, Park et al. 2015; Gong et al. 2017), an increase in TCW is observed over northern Canada (eastern Siberia), which corresponds to an increase in downward IR over northern Canada (eastern Siberia) (Figs. 5b,d). Moreover, the spatial patterns of the TCW trend are consistent with the downward IR (Fig. 5), which implies that an increase in TCW is crucial for the enhancement of the downward IR.

Insight into the moisture source for $\mathrm{TCW}$ can be gained by examining the lagged linear regression analysis of moisture flux convergence and evaporation. Figure 6 shows the trend of vertically integrated moisture flux vector, its convergence (multiplied by the latent heat of vaporization $L$ ), and evaporation during 1979-2016 (JJA), which is obtained by regressing the variables with IR1 index. From lag -6 (Fig. 6, top row) to lag 0 days (Fig. 6, fourth row), a quasi-stationary anticyclonic trend pattern of vertically integrated moisture flux can be seen around the Greenland region. A weak positive trend in moisture flux convergence can be seen over northern Canada that is accompanied by an increase in the southeasterly flux vector at lag -6 day. In addition, from lag -6 to lag 2 days (Fig. 6, bottom row), a negative trend in moisture flux convergence is centered over the anticyclonic pattern in Greenland. From lag -6 to lag 0 days, the moisture flux convergence over northern Canada has intensified and widened and finally extends to the inland of Canada. This feature is accompanied by the development of a cyclonic trend pattern, west of the anticyclonic trend pattern. In the positive lag period (from lag 0 to 2 days) the moisture flux convergence weakens rapidly because of weakening of the anticyclonic trend pattern and the associated southeasterly fluxes. Therefore, this anticyclonic trend pattern around the Greenland region and increase in the southeasterly fluxes over northern Canada are vital to the increase in moisture flux convergences over northern Canada. From lag -6 to lag 2 days, an increase in evaporation can be seen in the region between northeastern Canada and Greenland (Fig. 6, bottom row). However, the increase in evaporation is accompanied by the development of moisture flux convergence (Fig. 6), which implies that the changes in evaporation are mainly due to the increase in moisture flux convergence. This increase in evaporation is limited over the ocean, while the negative trend in evaporation is prominent over the land from lag -6 to lag 2 days. Furthermore, the magnitude of the moisture flux convergence (multiplied by $L$ ) trend is comparable to the downward IR trend (Fig. 4a), which suggests that the enhanced downward IR over northern Canada is mainly due to the increase of moisture flux convergence. Figure 7 shows the trend of the vertically integrated moisture flux vector, its convergence (multiplied by $L$ ), and evaporation during 1979-2016 (JJA), which is obtained by regressing the variables with the IR2 index. Over Siberia to the marginal seas in the north of Siberia, a quasi-stationary cyclonic trend pattern of moisture flux develops from lag -6 to lag 0 days (Fig. 7, top row). Along with the increase in the southwesterly flux vectors, an increasing trend in moisture flux convergence is found over eastern Siberia, which is consistent with the increasing trend in TCW (Fig. 5d). The moisture flux convergence over eastern Siberia has intensified with the development of the anticyclonic trend pattern downstream of the convergent region. Thereafter the moisture flux convergence weakens rapidly (from lag 0 to 2 days) because of the disappearance of the cyclonic trend pattern. On the other hand, decrease in evaporation can be seen over eastern Siberia (Fig. 7, bottom row), which implies that local processes cannot explain the increase in TCW over eastern Siberia. But the magnitude of the moisture flux convergence (multiplied by $L$ ) trend is comparable to the downward IR trend, which suggests that moisture flux convergence is a key factor controlling the trend in TCW over eastern Siberia. Therefore, we may conclude that the increase in TCW is mainly due to the moisture flux convergence, which contributes the most to the increase in downward IR through latent heat release.

\section{c. Possible causes of the circulation change}

The above results prove that the anticyclonic pattern around the Greenland region and the cyclonic pattern 

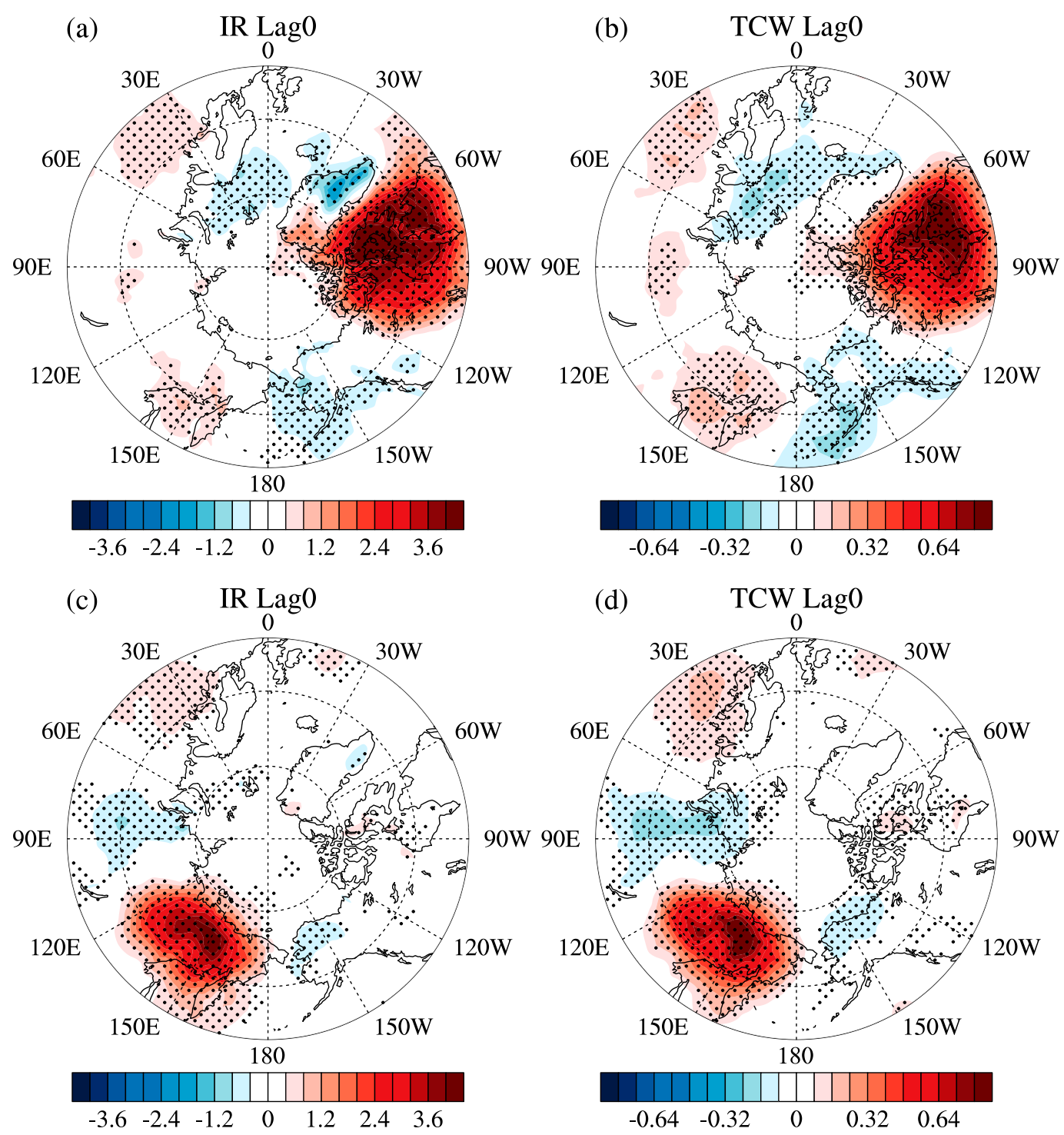

FIG. 5. Linear trends (decade ${ }^{-1}$ ) of (a) downward IR $\left(\mathrm{W} \mathrm{m}^{-2}\right)$ and (b) TCW $\left(\mathrm{kg} \mathrm{m}^{-2}\right)$ for the 1979-2016 JJA time period obtained by regressing these fields against the IR1 index. (c),(d) same as (a) and (b), respectively, but for the IR2 index. The lag chosen in each panel is lag 0 days. The dotted areas indicate the values that are statistical significant at the $95 \%$ confidence level.

from Siberia to the marginal seas in northern Siberia are closely associated with the changes in moisture flux convergence, TCW, and downward IR over northern Canada and eastern Siberia, respectively. The increase in strength of the anticyclonic and cyclonic pattern intensifies the moisture flux convergence, TCW, and downward IR over northern Canada and eastern Siberia, respectively. Now, we will investigate the spatial characteristics and possible mechanisms for the changes in atmospheric circulation pattern. Figure 8 shows the linear trend in summer-mean sea level pressure (SLP) and 200-hPa geopotential height (Z200) during 19792016. A decreasing trend in summer-mean SLP was observed from Siberia to the marginal seas in northern Siberia (Fig. 8a). The spatial pattern in SLP trend indicates a significant strengthening in westerly moisture flux and an increasing trend in moisture flux convergence over eastern Siberia. Summer-mean SLP increases over and around the Greenland ice sheet (Hanna et al. 2009), and it is accompanied by a significant strengthening in the southeasterly flux over northern Canada. To understand the physical mechanism causing the changes in SLP pattern, we focus on the changes in summer-mean 200-hPa geopotential height. There are little changes in $200-\mathrm{hPa}$ geopotential height on the Siberian side of the Arctic basin; however, the trend of the geopotential height is 

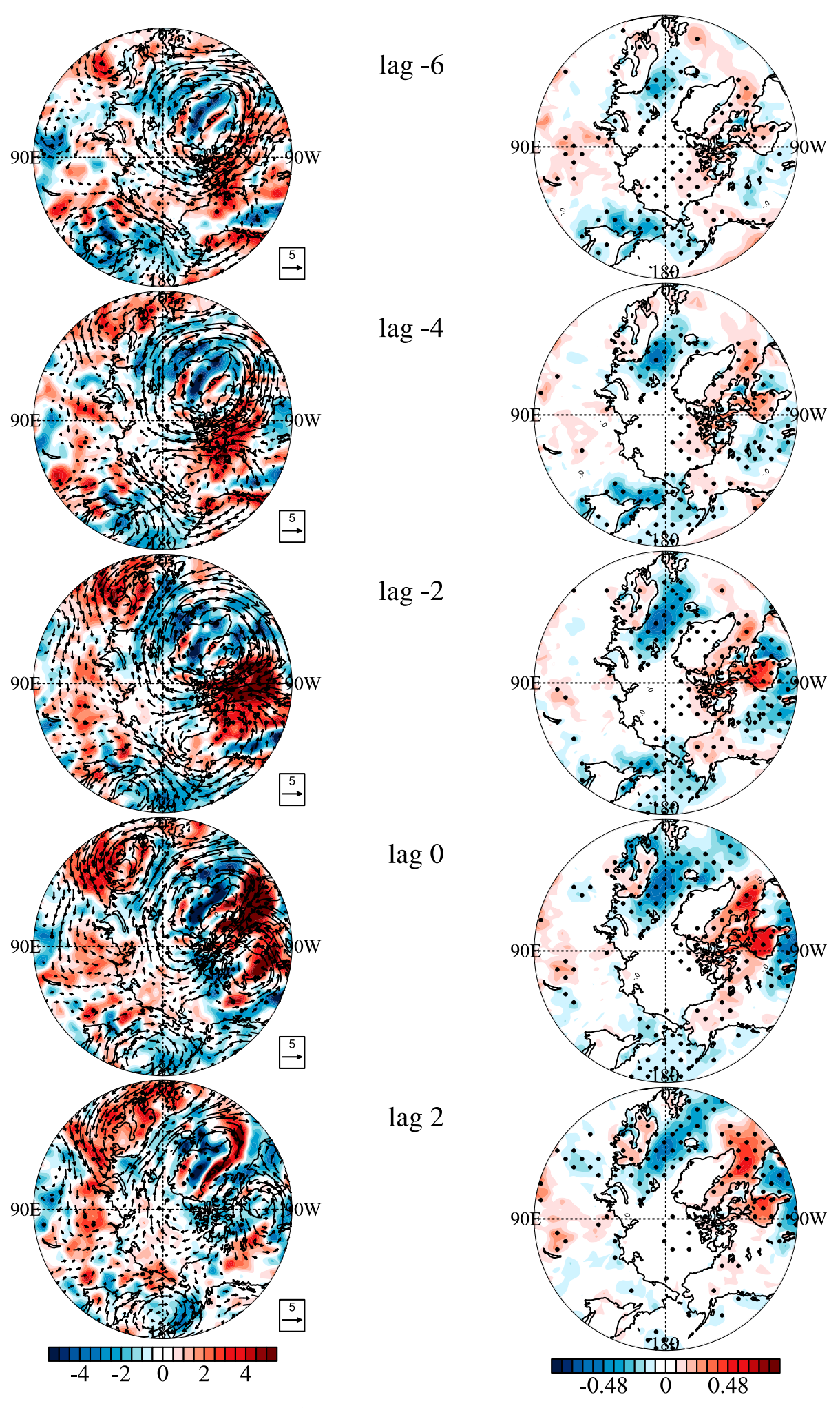

FIG. 6. Linear trends $\left(\right.$ decade $\left.^{-1}\right)$ of (left) the vertically integrated moisture flux vectors and moisture flux convergence multiplied by $L$ (color shading; $\mathrm{W} \mathrm{m}^{-2}$ ) and (right) evaporation $\left(\mathrm{mg} \mathrm{m}^{-2}\right.$ ) for the 1979-2016 JJA time period obtained by regressing these fields against the IR1 index. (top to bottom) The trends are shown from lag -6 through lag 2 days. The dotted areas indicate the values that are statistical significant at the $95 \%$ confidence level. 


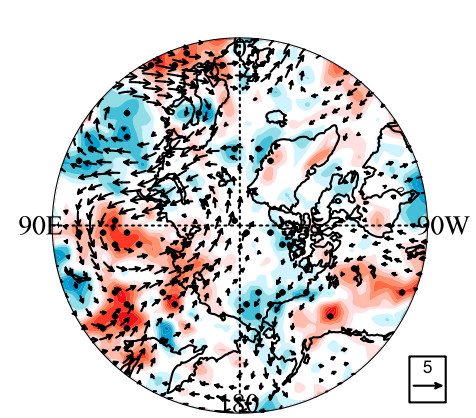

lag -6

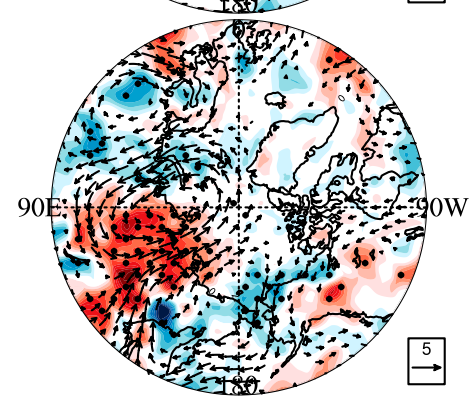

lag -4
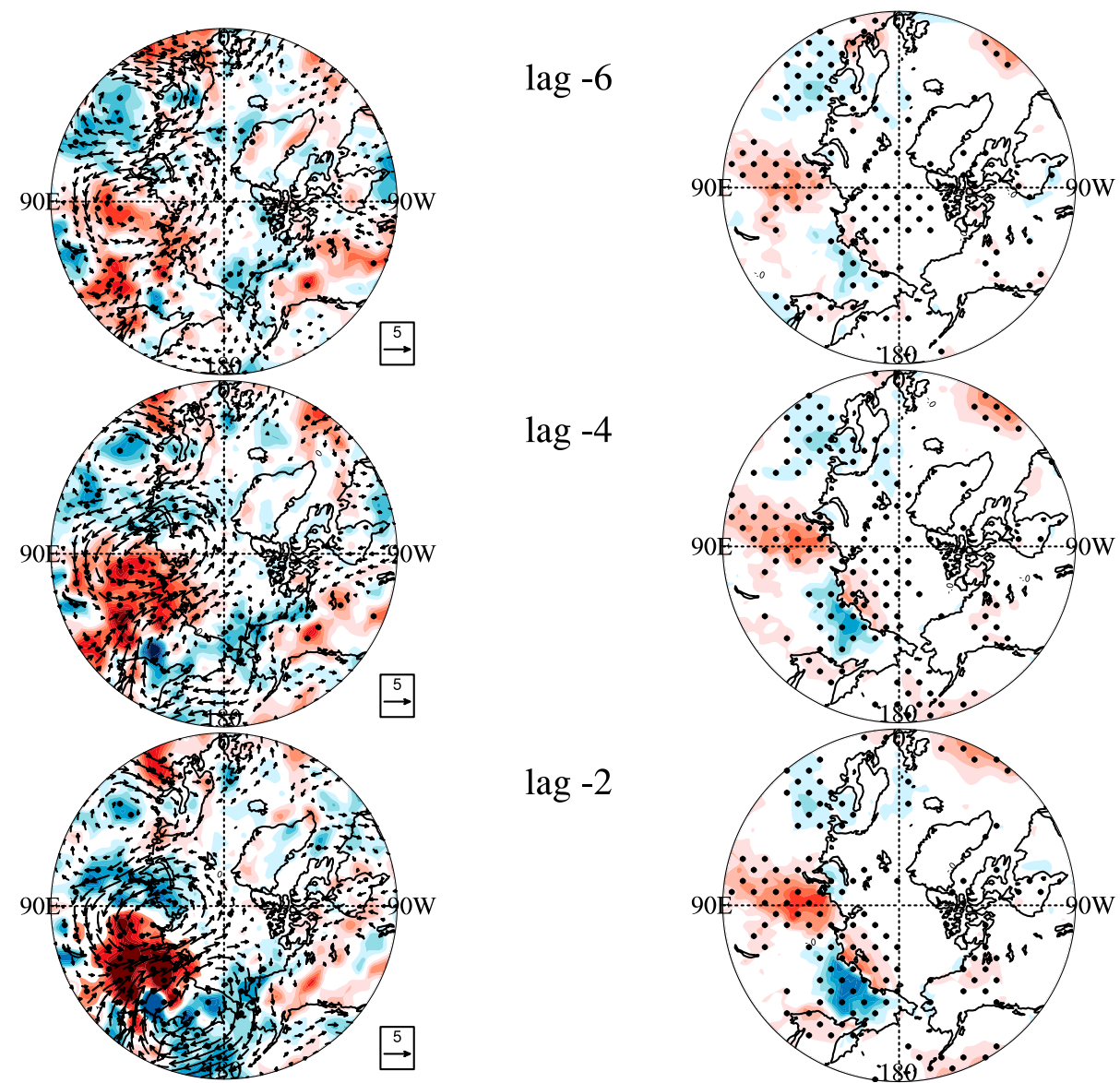

lag -2

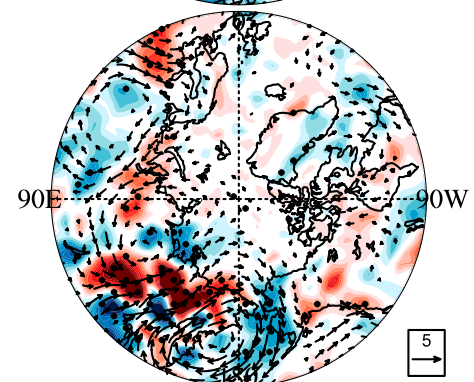

$\operatorname{lag} 0$
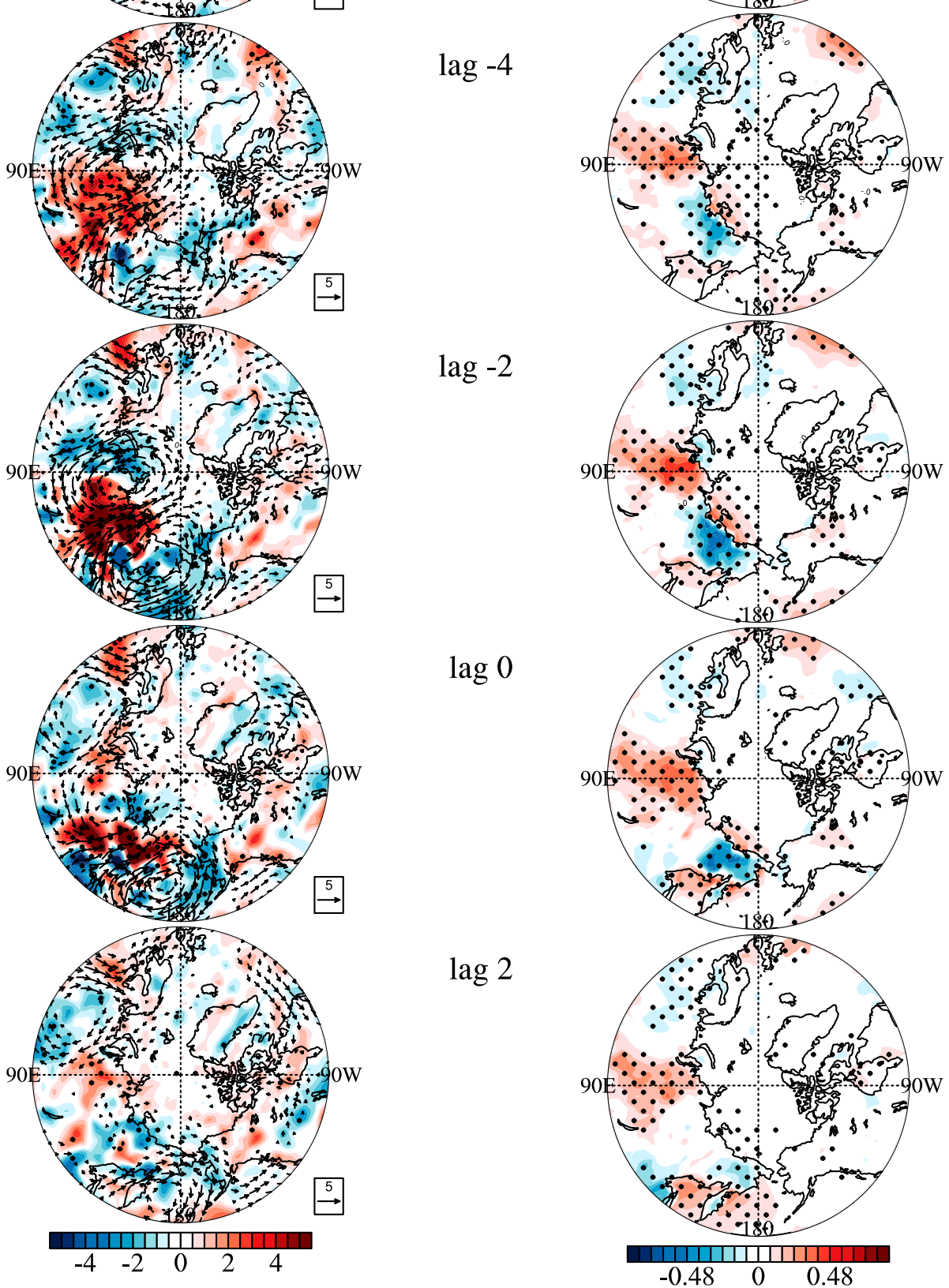

$\operatorname{lag} 2$

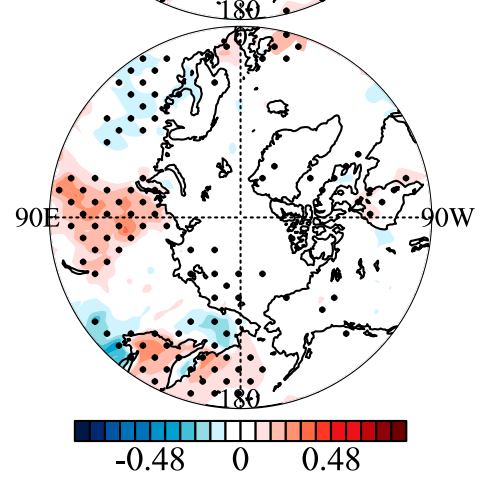

FIG. 7. As in Fig. 6, but for the IR2 index. 

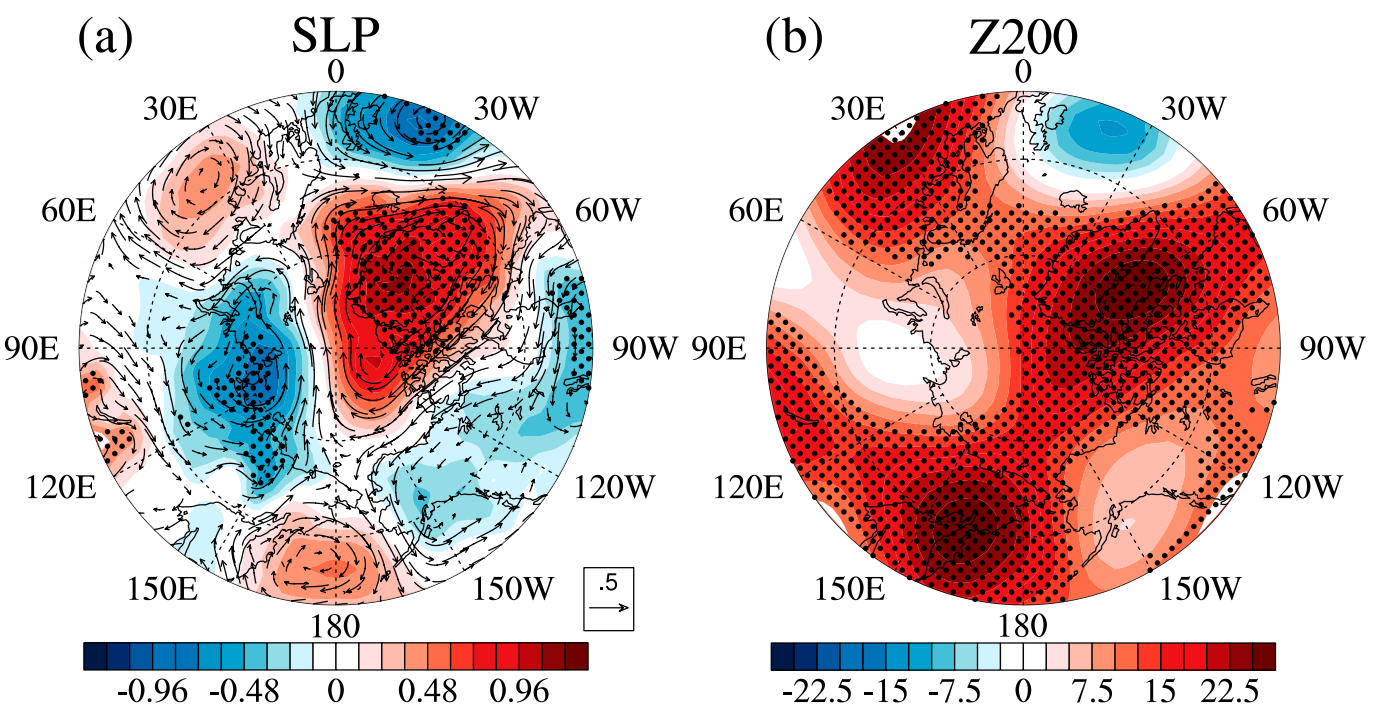

FIG. 8. Linear trends (decade ${ }^{-1}$ ) of summer-mean (a) sea level pressure (SLP; hPa) and 850-hPa wind (vectors; $\mathrm{m} \mathrm{s}^{-1}$ ) and (b) 200-hPa geopotential height (Z200; m) during 1979-2016. The dotted areas indicate the linear trends that are statistically significant at the $95 \%$ confidence level.

anticyclonic extending from Greenland northwestward to the Beaufort Sea (Fig. 8b). The SLP trend displays a dipole structure over Arctic, resembling the well-known Arctic dipole pattern (Wang et al. 2009; Overland et al. 2012; Overland and Wang 2010). The anticyclonic trend pattern generates relatively high pressure conditions and leads to more warm and wet air over the region between northeastern Canada and Greenland (Ding et al. 2014). Moreover, the high pressure around the Greenland region is also suggested to be responsible for the variability of the Arctic dipole pattern on the interannual and interdecadal time scales (Overland et al. 2012). The tendency toward a stronger anticyclonic circulation can lead to the changes in the shape and strength of the summer circumpolar vortex and relevant changes in the migration of storms (Serreze and Barrett 2008, 2011). The negative trend in SLP from Siberia to the marginal seas north of Siberia likely reflects more storms tracks over this region (Fujinami et al. 2016). This result indicates that the positive trend in the geopotential height over and around Greenland is the key factor causing the trend in SLP and the associated moisture flux transport.

The time evolution of the geopotential height around Greenland can be described by the GBI, which is defined by Fang (2004) and Hanna et al. (2013, 2015, 2016). We construct the GBI as domain-averaged geopotential height at $200 \mathrm{hPa}$ over the region $65^{\circ}-75^{\circ} \mathrm{N}, 60^{\circ}-90^{\circ} \mathrm{W}$. To illustrate the processes that link the changes in circulation due to surface temperature change, we display the linear trends in summer-mean surface temperature and downward IR that are linked to the trend in GBI in Figs. 9a and 9b. They show that both the geographic distribution and magnitude of the trend in these variables that are calculated by regressing them on GBI resemble the trends in these variables. We also display the time series of GBI and surface temperature change over eastern Siberia and northern Canada in Fig. 9c. The surface temperature changes over eastern Siberia and northern Canada are highly correlated with summer mean GBI, and the coefficients are 0.68 (0.47 after detrending) and 0.78 (0.61 after detrending), respectively. These statistical links between atmospheric circulation and temperature over eastern Siberia and northern Canada are robust both at interannual and decadal time scales, which confirms that the positive trend in the geopotential height around the Greenland region leads to an amplified warming over northern Canada and eastern Siberia.

Furthermore, an inspection of geopotential height field indicates that the high pressure center around the Greenland region is consistent throughout the troposphere (Figs. 9a,b), displaying a barotropic vertical structure around the Greenland region. Therefore, the enhanced blocking events might be the key factor for the positive trend in the geopotential height around the Greenland region. Previous studies have found that, since 2000, extremely high GBI events are clustered during the summer months (McLeod and Mote 2016; Hanna et al. 2018). However, the episodes of extremely high events are detected based on daily GBI values may not satisfy all of the established criteria for atmospheric blocking outlined in previous research (Tibaldi and Molteni 1990; Davini et al. 2012, 2014). Therefore, we use an index developed by Davini et al. 

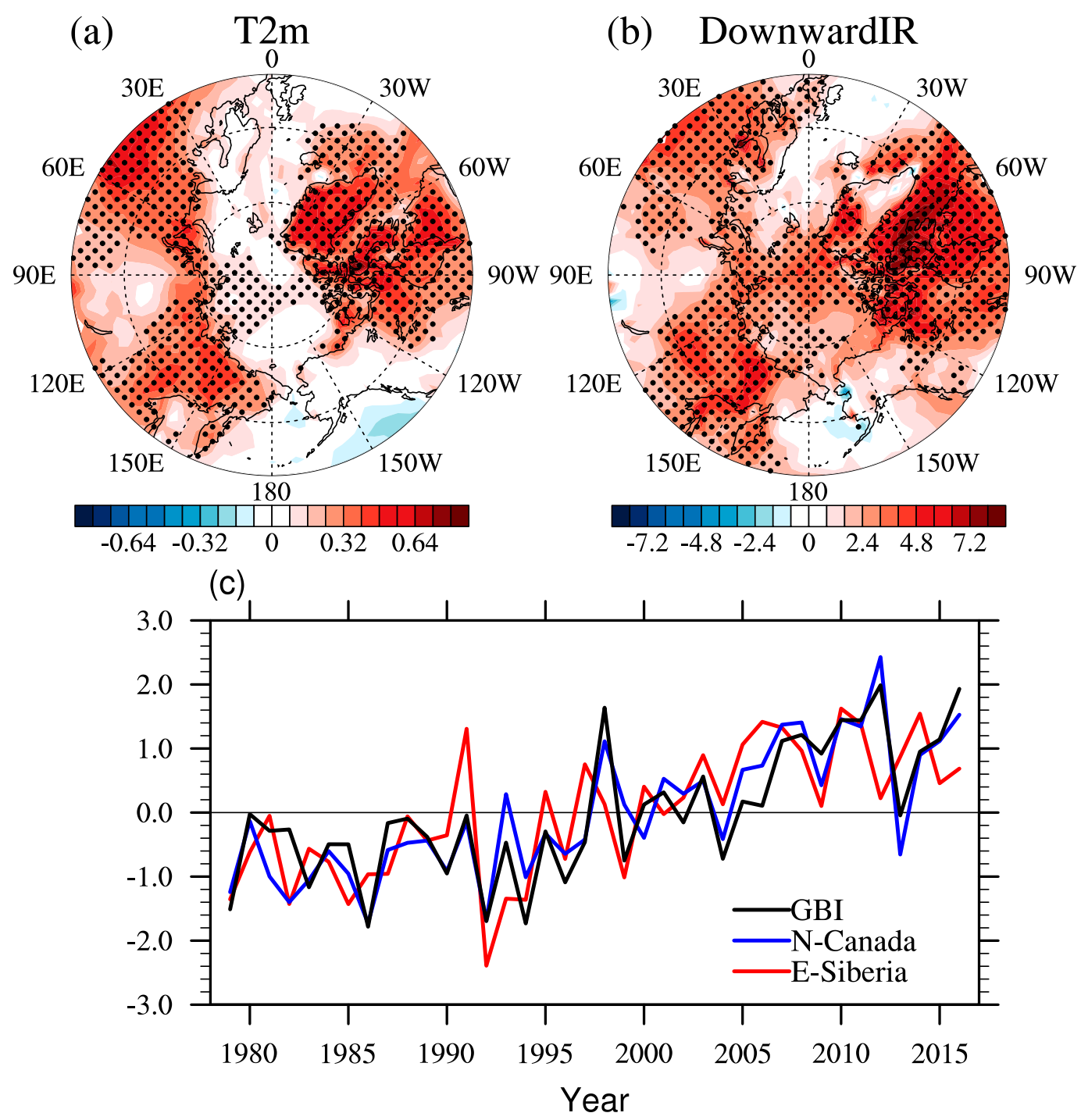

FIG. 9. Linear trends (decade ${ }^{-1}$ ) of (a) summer (JJA-averaged) surface air temperature (K) and (b) downward IR $\left(\mathrm{W} \mathrm{m}^{-2}\right)$ during 1979-2016 obtained by regressing these fields against the GBI. (c) Time series of GBI and summer-mean surface temperature averaged over eastern Siberia $\left(60^{\circ}-70^{\circ} \mathrm{N}, 120^{\circ}-170^{\circ} \mathrm{E}\right)$ and northern Canada $\left(55^{\circ}-72.5^{\circ} \mathrm{N}, 60^{\circ}-110^{\circ} \mathrm{W}\right)$ for the period $1979-2016$. Definition of the GBI is provided in the text. Amplitudes in (c) are scaled by one standard deviation of the corresponding time series.

(2012) to detect the blocking event, which is computed from meridional height gradients at midtroposphere. For comparison, we also employ a methodology to detect the blocking events as positive height anomalies in the midtroposphere and its persistence for five consecutive days (Tang et al. 2013; Liu et al. 2012). At first, we defined the Greenland region within a box bounded by $65^{\circ}-75^{\circ} \mathrm{N}, 30^{\circ}-60^{\circ} \mathrm{W}$. For each day, if at least a single grid point in the Greenland region is blocked, then the whole sector is considered to be blocked. Based on these two criteria, we construct the time series of the total number of blocking days and the average duration of blocking events from the daily blocking index for each summer season. Figure 10 shows the time series of the frequency and average duration of Greenland blocking based on positive height anomalies and meridional height gradients, respectively. In agreement with the previous studies, significant increase in the frequency of Greenland blocking are noted for summer months by applying the two different blocking identification methods (Figs. 10a,b). Using the method based on positive height anomalies, the time series of blocking frequencies over the Greenland region shows an increasing linear trend at a rate of 0.81 days per summer over 1979-2016, which is significant at the $99 \%$ confidence level. The time series of Greenland blocking frequency computed according 

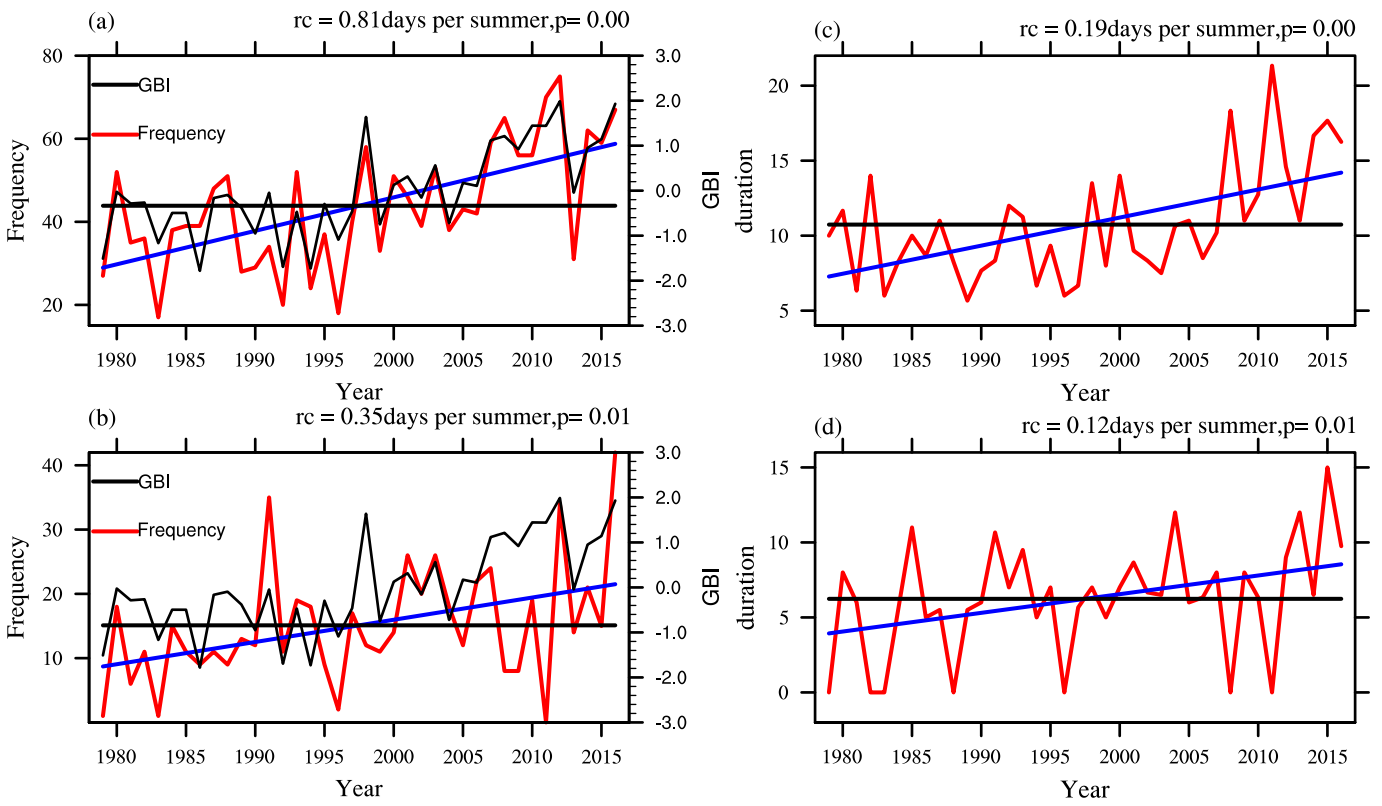

FIG. 10. Time series of summer-mean blocking frequency (days per summer) over the Greenland region using the method of (a) positive height and (b) meridional height gradients for the period 1979-2016. (c),(d) As in (a) and (b), respectively, but for the average duration (days) of event.

to meridional height gradients are computed according to meridional height gradients which are increasing at a rate of 0.35 days per summer (significant at the $99 \%$ confidence level) during 1979-2016. Furthermore, the blocking frequency time series based on positive height anomalies and summer mean GBI are highly correlated and the coefficient is 0.88 ( 0.81 after detrending), which implies the importance of Greenland blocking in driving the trend and interannual variability of GBI. Using meridional height gradient method, the actual Greenland blocking frequency is significantly correlated with summer mean GBI and the coefficient is 0.44 . However, when the linear trend is removed, the correlation coefficient between the two time series decreases to 0.23 . One possible explanation for the difference is that the blocking events identified by persistent geopotential height anomalies are influenced by large-scale changes in the geopotential height field, and this issue can be avoided by using the meridional height gradients method (Barnes et al. 2014). According to Davini et al. (2012), the Greenland blocking events lasts for $\sim 6-9$ days. As we can see in Fig. 10c, the average duration of positive geopotential height anomalies is 10.7 days, a bit longer than the average Greenland blocking duration. Furthermore, in the recent decade the duration of positive geopotential height anomalies has increased sharply at a rate of 0.19 days per summer during 1979-2016, which contributes significantly to the increase in the frequency of persistent geopotential height anomalies (Fig. 10c). Based on the meridional height gradients method, the average duration of the Greenland blocking event is 6.2 days, which matches well with the result of Davini et al. (2012). The linear trend in the duration of Greenland blocking event is 0.12 days per summer, which is significant at the $99 \%$ confidence level (Fig. 10d). Therefore, the increase in the average duration of Greenland blocking event plays an important role in the increase in the frequency of Greenland blocking events. Therefore, by applying two different blocking identification methods, the frequency of blocking events over Greenland during summer exhibits robust trends since 1979, which might have contributed partly to the tendency toward a stronger anticyclonic circulation over Greenland.

\section{Summary and discussion}

Previous studies have demonstrated that rapid surface warming events are pronounced over the Northern Hemisphere high-latitude land regions in summer. The warming trend that exceeds $0.5^{\circ} \mathrm{C}$ decade $^{-1}$ was mainly located over eastern Siberia, northern Canada, and Greenland. An enhanced downward IR is found to be the main driver for the stronger warming, which accounts for more than half of the warming trend over whole Arctic and $80 \%$ over northern Canada and eastern Siberia. The changes in the atmospheric circulation pattern play an important role, which enhances the downward IR over these regions. Summer-mean SLP decreases over and around Siberia, while it increases 
over the Greenland ice sheet regions. This configuration leads to the changes in moisture flux transport and abnormal moisture flux convergence over eastern Siberia and northern Canada. Furthermore, our analysis indicates that the changes in the configuration of SLP trends are resulting from an enhanced blocking activity and an associated positive trend in the geopotential height around the Greenland region, which is in agreement with previous studies.

This configuration of SLP trends caused by the positive trend in geopotential height around the Greenland region not only affects the land warming by transport of warmer and moister air but also accelerates the sea ice loss in summer through ice transport out of the central Arctic Ocean through the Fram Strait (Wang et al. 2009; B. Wu et al. 2016). However, we still do not know the exact causes underlying the enhanced blocking events over Greenland. Apart from the enhanced blocking activity, changes in external forcing are also responsible for stronger anticyclonic circulation. For example, regional warming over Greenland and the associated feedbacks due to ice melt are also enhancing the Greenland blocking events (Hanna et al. 2018). North Atlantic SSTs can strongly influence the circulation patterns in Greenland (Chylek et al. 2009; Häkkinen and Worthen 2011; Hanna et al. 2009) through the modification of the North Atlantic polar jet stream. Previous work identified that annual-mean atmospheric circulation around Greenland is closely associated with tropical SST variability (Ding et al. 2014). Ding et al. (2017) made an assumption that the SST trends across the tropical Pacific Ocean may contribute to the summer-mean high-latitude circulation variability. In recent decades, the Arctic sea ice during summer has experienced an accelerated decline (Comiso et al. 2008). Some observational studies show that the Arctic sea ice loss can induce circulation changes, reduce the zonal winds, and increase wave amplitudes in the summer season (Overland 2014; Tang et al. 2014). This hypothesis is based on strong covariability between the changes in circulation patterns and the sea ice; however, they did not prove the causality of the event. Alternatively, this covariability can be explained as a response of sea ice extent anomalies on the changes in temperature and atmospheric circulation instead of feedbacks of sea ice retreat onto the atmospheric circulation pattern. Some studies indicate that the changes in summer sea ice conditions have no significant impact on surface temperature, atmospheric humidity, and downward IR (Ding et al. 2017; Wu and Zhang 2010; Q. Wu et al. 2016).

However, despite strong observational evidence that atmospheric circulation plays the most significant role in driving the Arctic climate change during summer, summer AA can also lead to the changes in atmospheric circulation through weakening of meridional temperature gradients and increasing geopotential heights (Cohen et al. 2014; Francis and Vavrus 2012). Furthermore, additional research is necessary to elucidate whether these changes are anthropogenically forced or result from natural variations within the climate system.

Acknowledgments. We are thankful to ECMWF and GPCC for providing the reanalysis and observational datasets. This work is supported jointly by the National Natural Science Foundation of China (Grants 41750110484 and 41675061), the Ministry of Science and Technology of China (2016YFA0600604), and Key Research Program of Frontier Sciences, CAS (QYZDY-SSW-DQC024).

\section{REFERENCES}

Barnes, E. A., E. Dunn-Sigouin, G. Masato, and T. Woollings, 2014: Exploring recent trends in Northern Hemisphere blocking. Geophys. Res. Lett., 41, https://doi.org/10.1002/ 2013GL058745.

Brodzik, M. J., and R. Armstrong, 2013: Northern Hemisphere EASE-Grid 2.0 Weekly Snow Cover and Sea Ice Extent, Version 4. NASA National Snow and Ice Data Center Distributed Active Archive Center (subset used: January 1979 to December 2016), accessed 14 October 2018, https:// doi.org/10.5067/P7O0HGJLYUQU.

Brown, R., C. Derksen, and L. Wang, 2010: A multi-data set analysis of variability and change in Arctic spring snow cover extent, 1967-2008. Geophys. Res. Lett., 115, D16111, https:// doi.org/10.1029/2010JD013975.

Chen, Y., J. A. Francis, and J. R. Miller, 2002: Surface temperature of the Arctic: Comparison of TOVS satellite retrievals with surface observations. J. Climate, 15, 3698-3708, https://doi.org/ 10.1175/1520-0442(2002)015<3698:STOTAC >2.0.CO;2.

Chylek, P., C. K. Folland, G. Lesins, M. K. Dubey, and M. Wang, 2009: Arctic air temperature change amplification and the Atlantic multidecadal oscillation. Geophys. Res. Lett., 36 , 61-65, https://doi.org/10.1029/2009GL038777.

Cohen, J., and Coauthors, 2014: Recent Arctic amplification and extreme mid-latitude weather. Nat. Geosci., 7, 627-637, https://doi.org/10.1038/ngeo2234.

Comiso, J. C., C. L. Parkinson, R. Gersten, and L. Stock, 2008: Accelerated decline in the Arctic sea ice cover. Geophys. Res. Lett., 35, L01703, https://doi.org/10.1029/2007GL031972.

Coumou, D., and S. Rahmstorf, 2012: A decade of weather extremes. Nat. Climate Change, 2, 491-496, https://doi.org/ 10.1038/nclimate1452.

_ V. Petoukhov, S. Rahmstorf, S. Petri, and H. J. Schellnhuber, 2014: Quasi-resonant circulation regimes and hemispheric synchronization of extreme weather in boreal summer. Proc. Natl. Acad. Sci. USA, 111, 12331-12336, https://doi.org/ 10.1073/pnas.1412797111.

_ J. Lehmann, and J. Beckmann, 2015: The weakening summer circulation in the Northern Hemisphere mid-latitudes. Science, 348, 324-327, https://doi.org/10.1126/science.1261768.

Cox, C. J., V. P. Walden, and P. M. Rowe, 2012: A comparison of the atmospheric conditions at Eureka, Canada, and Barrow, Alaska.J. Geophys. Res., 117, D12204, https://doi.org/10.1029/ 2011JD017164. 
Davini, P., C. Cagnazzo, S. Gualdi, and A. Navarra, 2012: Bidimensional diagnostics, variability, and trends of Northern Hemisphere blocking. J. Climate, 25, 6496-6509, https:// doi.org/10.1175/JCLI-D-12-00032.1.

, P. G. Fogli, E. Manzini, S. Gualdi, and A. Navarra, 2014: European blocking and Atlantic jet stream variability in the NCEP/NCAR reanalysis and the CMCC-CMS climate model. Climate Dyn., 43, 71-85, https://doi.org/10.1007/ s00382-013-1873-y.

Davy, R., L. Chen, and E. Hanna, 2018: Arctic amplification metrics. Int. J. Climatol., 38, 4384-4394, https://doi.org/ 10.1002/joc.5675.

Dee, D. P., and Coauthors, 2011: The ERA-Interim reanalysis: Configuration and performance of the data assimilation system. Quart. J. Roy. Meteor. Soc., 137, 553-597, https://doi.org/ 10.1002/qj.828.

Ding, Q., J. M. Wallace, D. S. Battisti, E. J. Steig, A. J. Gallant, H. J. Kim, and L. Geng, 2014: Tropical forcing of the recent rapid Arctic warming in northeastern Canada and Greenland. Nature, 509, 209-212, https://doi.org/10.1038/nature13260.

_- , and Coauthors, 2017: Influence of high-latitude atmospheric circulation changes on summertime Arctic sea ice. Nat. Climate Change, 7, 289-295, https://doi.org/10.1038/ nclimate 3241

Doyle, J. G., G. Lesins, C. P. Thackray, C. Perro, G. J. Nott, T. J. Duck, R. Damoah, and J. R. Drummond, 2011: Water vapor intrusions into the High Arctic during winter. Geophys. Res. Lett., 38, 99-108, https://doi.org/10.1029/2011GL047493.

Fan, Y., and H. V. D. Dool, 2004: Climate Prediction Center global monthly soil moisture data set at $0.5^{\circ}$ resolution for 1948 to present. J. Geophys. Res., 109, D10102, https://doi.org/10.1029/ 2003JD004345.

Fang, Z.-F., 2004: Statistical relationship between the Northern Hemisphere sea ice and atmospheric circulation during winter time. Observation, Theory and Modeling of Atmospheric Variability, X. Zhu, Ed., World Scientific Series on Meteorology of East Asia, Vol. 3, World Scientific, 131-141.

Feldstein, S. B., 2003: The dynamics of NAO teleconnection pattern growth and decay. Quart. J. Roy. Meteor. Soc., 129, 901-924, https://doi.org/10.1256/qj.02.76.

Francis, J. A., and S. J. Vavrus, 2012: Evidence linking Arctic amplification to extreme weather in mid-latitudes. Geophys. Res. Lett., 39, L06801, https://doi.org/10.1029/2012GL051000.

_- and N. Skific, 2015: Evidence linking rapid Arctic warming to mid-latitude weather patterns. Philos. Trans., 373A, 20140170 https://doi.org/10.1098/rsta.2014.0170.

— in response to rapid Arctic warming. Environ. Res. Lett., 10, 014005, https://doi.org/10.1088/1748-9326/10/1/014005.

Fujinami, H., T. Yasunari, and T. Watanabe, 2016: Trend and interannual variation in summer precipitation in eastern Siberia in recent decades. Int. J. Climatol., 36, 355-368, https://doi.org/ $10.1002 /$ joc. 4352.

Gong, T., and D. Luo, 2017: Ural blocking as an amplifier of the Arctic sea ice decline in winter. J. Climate, 30, 2639-2654 https://doi.org/10.1175/JCLI-D-16-0548.1.

- - S. Feldstein, and S. Lee, 2017: The role of downward infrared radiation in the recent Arctic winter warming trend. J. Climate, 30, 4937-4949, https://doi.org/10.1175/ JCLI-D-16-0180.1.

Groisman, P. Ya., R. W. Knight, V. N. Razuvaev, O. N. Bulygina, and T. R. Karl, 2006: State of the ground: Climatology and changes during the past 69 years over northern Eurasia for a rarely used measure of snow cover and frozen land. J. Climate, 19, 4933-4955, https://doi.org/10.1175/JCLI3925.1.

Häkkinen, S., and D. L. Worthen, 2011: Atmospheric blocking and Atlantic multidecadal ocean variability. Science, 334, 655-659, https://doi.org/10.1126/science.1205683.

Hanna, E., J. Cappelen, X. Fettweis, P. Huybrechts, A. Luckman, and M. H. Ribergaard, 2009: Hydrologic response of the Greenland ice sheet: The role of oceanographic warming. Hydrol. Processes, 23, 7-30, https://doi.org/10.1002/hyp.7090.

, J. M. Jones, J. Cappelen, S. H. Mernild, L. Wood, K. Steffen, and P. Huybrechts, 2013: The influence of North Atlantic atmospheric and oceanic forcing effects on 1900-2010 Greenland summer climate and ice melt/runoff. Int. J. Climatol., 33, 862-880, https://doi.org/10.1002/joc.3475.

, T. E. Cropper, P. D. Jones, A. A. Scaife, and R. Allan, 2015: Recent seasonal asymmetric changes in the NAO (a marked summer decline and increased winter variability) and associated changes in the AO and Greenland Blocking Index. Int. J. Climatol., 35, 2540-2554, https://doi.org/10.1002/joc.4157.

,,- R. J. Hall, and J. Cappelen, 2016: Greenland Blocking Index 1851-2015: A regional climate change signal. Int. J. Climatol., 36, 4847-4861, https://doi.org/10.1002/joc.4673.

$\longrightarrow$, R. J. Hall, T. E. Cropper, T. J. Ballinger, L. Wake, T. Mote, and J. Cappelen, 2018: Greenland Blocking Index daily series 1851-2015: Analysis of changes in extremes and links with North Atlantic and UK climate variability and change. Int. J. Climatol., 38, 3546-3564, https://doi.org/10.1002/joc.5516.

Johannessen, O. M., and Coauthors, 2004: Arctic climate change: Observed and modeled temperature and sea-ice variability. Tellus, 56A, 559-560, https://doi.org/10.1111/ j.1600-0870.2004.00092.x.

Lee, S., S. Feldstein, D. Pollard, and T. White, 2011a: Do planetary wave dynamics contribute to equable climates? J. Climate, $\mathbf{2 4}$, 2391-2404, https://doi.org/10.1175/2011JCLI3825.1.

, T. Gong, N. Johnson, S. B. Feldstein, and D. Pollard, 2011b: On the possible link between tropical convection and the Northern Hemisphere Arctic surface air temperature change between 1958 and 2001. J. Climate, 24, 4350-4367, https://doi.org/10.1175/2011JCLI4003.1.

,-- S. B. Feldstein, J. A. Screen, and I. Simmonds, 2017: Revisiting the cause of the 1989-2009 Arctic surface warming using the surface energy budget: Downward infrared radiation dominates the surface fluxes. Geophys. Res. Lett., 44, 10 654-10 661, https://doi.org/10.1002/2017GL075375.

Lehmann, J., and D. Coumou, 2015: The influence of mid-latitude storm tracks on hot, cold, dry and wet extremes. Sci. Rep., 5, 17491, https://doi.org/10.1038/srep17491.

Lesins, G., T. J. Duck, and J. R. Drummond, 2012: Surface energy balance framework for Arctic amplification of climate change. J. Climate, 25, 8277-8288, https://doi.org/10.1175/ JCLI-D-11-00711.1.

Liu, J., J. Curry, and H. Wang, 2012: Impact of declining Arctic sea ice on winter snowfall. Proc. Natl. Acad. Sci. USA, 109, 40744079, https://doi.org/10.1073/pnas.1114910109.

Mann, H. B., 1945: Nonparametric tests against trend. Econometrica, 13, 245-259, https://doi.org/10.2307/1907187.

Matsumura, S., and K. Yamazaki, 2012: Eurasian subarctic summer climate in response to anomalous snow cover. J. Climate, 25, 1305-1317, https://doi.org/10.1175/2011JCLI4116.1.

,,- , and T. Tokioka, 2010: Summertime land-atmosphere interactions in response to anomalous springtime snow cover in northern Eurasia. J. Geophys. Res., 115, D20107, https:// doi.org/10.1029/2009JD012342. 
McLeod, J. T., and T. L. Mote, 2016: Linking interannual variability in extreme Greenland blocking episodes to the recent increase in summer melting across the Greenland ice sheet. Int. J. Climatol., 36, 1484-1499, https://doi.org/10.1002/joc.4440.

Overland, J. E., 2014: Atmospheric science: Long-range linkage. Nat. Climate Change, 4, 11-12, https://doi.org/10.1038/ nclimate2079.

- and M. Wang, 2010: Large-scale atmospheric circulation changes are associated with the recent loss of Arctic sea ice. Tellus, 62, 1-9, https://doi.org/10.1111/j.1600-0870.2009.00421.x. , and S. Salo, 2008: The recent Arctic warm period. Tellus, 60A, 589-597, https://doi.org/10.1111/j.1600-0870.2008.00327.x.

, J. A. Francis, E. Hanna, and M. Wang, 2012: The recent shift in early summer Arctic atmospheric circulation. Geophys. Res. Lett., 39, L19804, https://doi.org/10.1029/2012GL053268.

— weather to the changing Arctic. Nat. Climate Change, 6, 992999, https://doi.org/10.1038/nclimate3121.

Park, D. S. R., S. Lee, and S. B. Feldstein, 2015: Attribution of the recent winter sea ice decline over the Atlantic sector of the Arctic Ocean. J. Climate, 28, 4017-4033, https://doi.org/ 10.1175/JCLI-D-15-0042.1.

Peterson, T. C., M. P. Hoerling, P. A. Stott, and S. C. Herring, 2013: Explaining Extreme Events of 2012 from a Climate Perspective. Bull. Amer. Meteor. Soc., 94, S1-S74, https://doi.org/ 10.1175/BAMS-D-13-00085.1.

Polyakov, I. V., R. V. Bekryaev, G. V. Alekseev, U. S. Bhatt, R. L. Colony, M. A. Johnson, A. P. Maskshtas, and D. Walsh, 2003: Variability and trends of air temperature and pressure in the maritime Arctic, 1875-2000. J. Climate, 16, 2067-2077, https://doi.org/10.1175/1520-0442(2003)016<2067: VATOAT $>2.0 . \mathrm{CO} ; 2$.

Schneider, U., A. Becker, P. Finger, A. Meyer-Christoffer, B. Rudolf, and M. Ziese, 2011: GPCC full data reanalysis version 6.0 at $1.0^{\circ}$ : Monthly land-surface precipitation from rain-gauges built on GTS-based and historic data. Global Precipitation Climatology Centre hosted at Deutscher Wetterdienst (DWD), accessed 18 October 2018, https://doi.org/ 10.5676/DWD_GPCC/FD_M_V6_100.

Screen, J. A., and I. Simmonds, 2010a: The central role of diminishing sea ice in recent Arctic temperature amplification. Nature, 464, 1334-1337, https://doi.org/10.1038/nature09051.

—_, and _ 2010b: Increasing fall-winter energy loss from the Arctic Ocean and its role in Arctic temperature amplification. Geophys. Res. Lett., 37, L16707, https://doi.org/10.1029/ 2010GL044136.

Serreze, M. C., and A. P. Barrett, 2008: The summer cyclone maximum over the central Arctic Ocean. J. Climate, 21, 10481065, https://doi.org/10.1175/2007JCLI1810.1.

$\longrightarrow$, and - 2011: Characteristics of the Beaufort Sea High. J. Climate, 24, 159-182, https://doi.org/10.1175/2010JCLI3636.1. , and R. G. Barry, 2011: Processes and impacts of Arctic amplification: A research synthesis. Global Planet. Change, 77, 85-96, https://doi.org/10.1016/j.gloplacha.2011.03.004.

, A. P. Barrett, J. C. Stroeve, and D. N. Kindig, 2009: The emergence of surface-based Arctic amplification. Cryosphere, 3, 11-19, https://doi.org/10.5194/tc-3-11-2009.
Shi, X., M. Wild, and D. P. Lettenmaier, 2010: Surface radiative fluxes over the pan-Arctic land region: Variability and trends. J. Geophys. Res., 115, D22104, https://doi.org/ 10.1029/2010JD014402.

Sutton, R. T., and B. Dong, 2012: Atlantic Ocean influence on a shift in European climate in the 1990s. Nat. Geosci., 5, 788792, https://doi.org/10.1038/ngeo1595.

Tang, Q., X. Zhang, X. Yang, and J. A. Francis, 2013: Cold winter extremes in northern continents linked to Arctic sea ice loss. Environ. Res. Lett., 8, 014036, https://doi.org/ 10.1088/1748-9326/8/1/014036.

_ _ _ and J. A. Francis, 2014: Extreme summer weather in northern mid-latitudes linked to a vanishing cryosphere. Nat. Climate Change, 4, 45-50, https://doi.org/10.1038/nclimate2065

Tibaldi, S., and F. Molteni, 1990: On the operational predictability of blocking. Tellus, 42, 343-365, https://doi.org/ 10.3402/tellusa.v42i3.11882.

Trenberth, K. E., J. T. Fasullo, G. Branstator, and A. S. Phillips, 2014: Seasonal aspects of the recent pause in surface warming. Nat. Climate Change, 4, 911-916, https://doi.org/10.1038/ nclimate2341.

Walsh, J. E., and W. L. Chapman, 1998: Arctic cloud-radiationtemperature associations in observational data and atmospheric reanalyses. J. Climate, 11, 3030-3045, https://doi.org/ 10.1175/1520-0442(1998)011<3030:ACRTAI>2.0.CO;2.

Wang, J., J. Zhang, E. Watanabe, M. Ikeda, K. Mizobata, J. E. Walsh, X. Bai, and B. Wu, 2009: Is the dipole anomaly a major driver to record lows in Arctic summer sea ice extent? Geophys. Res. Lett., 36, L05706, https://doi.org/10.1029/ 2008 GL036706.

Woods, C., R. Caballero, and G. Svensson, 2013: Large-scale circulation associated with moisture intrusions into the Arctic during winter. Geophys. Res. Lett., 40, 4717-4721, https://doi.org/10.1002/grl.50912.

World Meteorological Organization, 2011: Weather extremes in a changing climate: Hindsight on foresight. WMO 1075, 20 pp., https://library.wmo.int/pmb_ged/wmo_1075_en.pdf.

Wu, B., K. Yang, and J. A. Francis, 2016: Summer Arctic dipole wind pattern affects the winter Siberian High. Int. J. Climatol., 36, 4187-4201, https://doi.org/10.1002/joc.4623.

Wu, Q., and X. Zhang, 2010: Observed forcing-feedback processes between Northern Hemisphere atmospheric circulation and Arctic sea ice coverage. J. Geophys. Res., 115, D14119, https:// doi.org/10.1029/2009JD013574.

—, L. Cheng, D. Chan, Y. Yao, H. Hu, and Y. Yao, 2016: Suppressed midlatitude summer atmospheric warming by Arctic sea ice loss during 1979-2012. Geophys. Res. Lett., 43, 2792 2800, https://doi.org/10.1002/2016GL068059.

Yasunari, T., A. Kitoh, and T. Tokioka, 1991: Local and remote responses to excessive snow mass over Eurasia appearing in the northern spring and summer climate: A study with the MRI GCM. J. Meteor. Soc. Japan, 69, 473-487, https://doi.org/ 10.2151/jmsj1965.69.4_473.

Zib, B. J., X. Dong, B. Xi, and A. Kennedy, 2012: Evaluation and intercomparison of cloud fraction and radiative fluxes in recent reanalyses over the Arctic using BSRN surface observations. J. Climate, 25, 2291-2305, https://doi.org/10.1175/ JCLI-D-11-00147.1. 